\title{
Lesões faciais e protetores bucais na prática desportiva
}

http://dx.doi.org/10.11606/1807-5509201900010127

\author{
Yuri Victor de Medeiros MARTINS* \\ Isabela Pinheiro Cavalcanti LIMA*/** \\ Marquiony Marques dos SANTOS ${ }^{* *}$
}

*Universidade do Estado do Rio Grande do Norte, Mossoró, $\mathrm{RN}$, Brasil. ${ }^{* *}$ Universidade Federal do Rio Grande do Norte Natal, RN, Brasil.

\section{Resumo}

São muitos os acidentes esportivos que resultam em traumas faciais. 0 uso dos protetores bucais torna-se imprescindivel como medida de proteção dos atletas. 0 objetivo do estudo foi quantificar e qualificar as lesões orofaciais decorrentes da prática desportiva, assim como traçar um paralelo com o uso dos protetores bucais. Para tanto realizou-se um estudo transversal e descritivo compreendendo 248 praticantes de oito modalidades esportivas distintas da Paraíba e do Rio Grande do Norte. A investigação contou com a aplicação de um questionário já validado na literatura. Os dados obtidos receberam um tratamento estatístico pelo Teste Exato de Fisher $(p<0,05)$ bem como foram analisados por meio de estatística descritiva, o programa responsável foi o SPSS 20.0. Cerca de $80 \%$ dos indivíduos já sofreram um trauma facial durante sua vida esportiva, com a lesão de tecido mole e a fratura dental como mais comum. A quase totalidade dos indivíduos $(92,7 \%)$ afirmou conhecer os protetores bucais. 223 esportistas $(89,9 \%)$ já usaram o protetor bucal em algum momento de sua vida esportiva, porém apenas $50 \%$ relataram o uso rotineiro. Já em relação ao tipo de protetor bucal utilizado, esta pesquisa trás o tipo termoplástico com $71,4 \%$ do total $(n=177)$. As lesões orofaciais fazem parte da rotina dos atletas. No entanto, as pessoas envolvidas no meio esportivo como um todo ainda não prestam a devida importância ao tema. Sendo assim, recomenda-se o surgimento de políticas de regularização do uso do protetor bucal nos esportes e também a divulgação dos benefícios que a proteção e a prevenção trazem aos atletas.

Palavras-Chave: Esportes; Ferimentos e lesões; Odontologia; Saúde bucal; Educação Física e treinamento.

\section{Introdução}

A Organização Mundial de Saúde (OMS) possui uma definição simplória e, ao mesmo tempo, utópica para a saúde; não como a simples ausência de doença, mas uma situação de perfeito bem-estar físico, mental e social ${ }^{1}$. Em tempos de hoje, o que mais se aproxima da conceituação de saúde é a sua aproximação com o conceito de qualidade de vida ${ }^{2}$. Em suma, a saúde pode ser entendida como manifestação da harmonia do corpo em sintonia com todos os fatores pertinentes a vida humana ${ }^{3}$.

A lesão, injúria ou traumatismo orofacial pode ser definido como uma agressão mecânica, térmica ou química sofrida pelo dente ou pelas outras estruturas da face e do crânio, possuindo tipo, intensidade e causas variadas; e representa um problema de saúde relevante na sociedade contemporânea ${ }^{4}$.
Ao longo dos últimos anos, a prática das artes marciais tem se difundido em todo o mundo e, também, no Brasil. Na nossa realidade nacional, esses esportes destacam-se ainda mais com os recentes resultados expressivos alcançados pelos atletas, especialmente no MMA (artes marciais mistas) e no judô 5 .

Os esportes coletivos, aqui representados pelo basquete, futebol e futsal são praticados abundantemente em várias regióes do mundo. $\mathrm{O}$ futebol é reconhecido internacionalmente como a paixão nacional dos brasileiros, e o futsal, sua variante, também agrada grande parte da população no Brasil ${ }^{6,7}$.

Protetor bucal é um dispositivo flexível ou aparelho adaptado no interior e/ou exterior da cavidade bucal com o objetivo de reduzir as lesóes faciais. Desse modo, reduz a incidência de lesão 
orofacial durante a participação esportiva ${ }^{8}$. Existem vários tipos de protetores bucais no mercado, notadamente os tipos I, II, III. Sendo o tipo III aquele que fornece o maior nível de proteção ao atleta e é devidamente confeccionado pelo cirurgiáo dentista. Porém, é sabido que nem todos os atletas usam ou sabem da importância do uso desses protetores. Entretanto, vários estudos apontam como imprescindível o uso desses equipamentos durante treinamentos e competiçóes?

\section{Método}

Seguindo as normas éticas da resolução 466/12 do Conselho Nacional de Saúde do Brasil, proferiu-se uma pequena palestra aos esportistas previamente, com o intuito de esclarecimentos sobre a natureza e o objetivo da pesquisa e sua consequente importância para o meio científico e profissional.

Inicialmente foi realizada uma seleçâo dos clubes e academias nos municípios de Santa Luzia, São Mamede e Patos na PB; e Caicó, Parelhas e Equador no RN. Em seguida o pesquisador entrou em contato com os responsáveis obtendo consentimento para a realização da pesquisa.

Após uma palestra prévia, foi aplicado um questionário adaptado do questionário já validado de Perunski et al. ${ }^{11}$. Para caracterização da amostra, foram incluídas perguntas a respeito da idade, gênero, grau de profissionalismo, tempo de prática e esporte praticado. Sobre as lesões orofaciais, perguntou-se a respeito da presença e do tipo de lesão sofrida. Também foi questionado quanto ao conhecimento, à importância e a utilização do protetor bucal, assim como o tipo de dispositivo utilizado.

\section{Tipo de estudo}

Pesquisa transversal, de caráter descritivo, realizada com praticantes de artes marciais e esportes coletivos da região Sertão da Paraíba/PB
A possibilidade de deformidade permanente e as consequências emocionais geram destaque ao trauma facial. Aliado a isso, observa-se que nas últimas décadas houve um aumento significativo dos traumas faciais, tendo como causas o acidente automobilístico, as quedas e a prática de esportes ${ }^{10}$.

Sendo assim, objetiva-se realizar um levantamento sobre as lesōes orofaciais decorridas da prática desportiva, e ao mesmo tempo, correlacioná-las com a modalidade esportiva e o uso dos protetores bucais.

e da região Seridó do Rio Grande do Norte/RN, do Brasil.

\section{Sujeitos da pesquisa}

Mediante levantamento prévio nas regióes citadas acima, 700 indivíduos praticam esportes de forma amadora ou profissional, compondo o universo da pesquisa. De acordo com os cálculos estatísticos fornecidos pelo programa BioEstat 5.0, chega-se a uma amostra de 248 esportistas, praticantes das artes marciais: muay thai, jiu-jítsu, boxe, caratê e MMA; e dos esportes coletivos: futebol, futsal e basquete. Foram incluídos todos os esportistas de 18 a 50 anos, de ambos os sexos. Os sujeitos que náo concordaram com a pesquisa e desprezaram a assinatura do TCLE, foram excluídos do levantamento.

\section{Análise estatística}

Os dados foram analisados por meio de estatística descritiva (distribuiçóes absolutas e percentuais, média, mediana e desvio-padrão) e analítica (teste do Qui-quadrado ou Exato de Fisher, Odds Ratio e Regressão Logística). O nível de significância adotado foi de 5\%. Como ferramentas estatísticas, utilizou-se o programa estatístico SPSS (Statistical Package for the Social Sciences) na versão 20.0 e o programa de tabulação Office Excel 2010.

\section{Resultados}

Foram analisados os questionários de 248 pessoas, sendo 130 de academias paraibanas e 118 potiguares. Seguindo-se um padrão de homogeneidade e verificando a ausência de dados significativos, optouse por tratar os resultados de forma conjunta. Dito isso, a TABELA 1 descreve a amostra em relaçáo ao sexo, 
a faixa etária, ao grau de profissionalismo e ao tempo de prática esportiva.

Cerca de um terço dos atletas optaram por praticar os esportes coletivos de contato. A polarização dos sujeitos em direção às lutas pode ser explicada pela cobertura compulsiva que a mídia vem fazendo sobre essas modalidades e por elas representarem duas categorias a mais no rol de esportes dessa pesquisa. Como fiel representante da categoria de esportes de contato, as lutas, em especial o MMA, destaca-se nessa pesquisa quando do aparecimento de lesóes orofaciais mesmo com o uso do protetor bucal. Logo em seguida, a TABELA 2 ilustra a análise de associação entre o uso de protetor no momento da lesão e os tipos de esportes praticados dos sujeitos da pesquisa.

Já em relaçâo ao tipo de protetor bucal utilizado, esta pesquisa apresenta o tipo termoplástico como o mais escolhido. Acredita-se que o principal motivo para a ampla aquisição e uso dos protetores termoplásticos seja o fácil acesso, uma vez que são vendidos em lojas de artigos de esportes e farmácias, além do baixo custo e a simplicidade da técnica para confecção. A TABELA 3 confirmará os resultados sobre os tipos de protetores bucais e trará outras informaçóes a respeito do uso e do conhecimento por parte dos esportistas.

TABELA 1 - Caracterização da amostra

\begin{tabular}{llcc}
\hline Variáves & Categorias & n & \% \\
\hline Sexo & Masculino & 173 & 69,8 \\
& Feminino & 75 & 30,2 \\
Idade & Até 24 Anos & 106 & 42,7 \\
& 25 A 27 Anos & 74 & 29,8 \\
\multirow{4}{*}{ Profissionalismo } & 28 Anos Ou Mais & 68 & 27,4 \\
& Amador & 204 & 82,3 \\
Tempo de Prática & Profissional & 44 & 17,7 \\
& Até 3 Anos & 115 & 46,4 \\
& 4 A 5 Anos & 69 & 27,8 \\
& 6 Anos Ou Mais & 64 & 25,8 \\
\hline
\end{tabular}

TABELA 2 - Relação entre o uso de protetor bucal e o esporte praticado

\begin{tabular}{|c|c|c|c|c|c|c|}
\hline Variáves & Categorias & $\mathbf{n}(\%)$ & $\mathbf{n}(\%)$ & RP & IC 95\% & Valor de $p$ \\
\hline \multirow[t]{2}{*}{ Basquete } & Sim & $9(60,0 \%)$ & $6(40,0 \%)$ & 0,83 & $0,54-1,27$ & 0,309 \\
\hline & Não & $136(72,3 \%)$ & $52(27,7 \%)$ & & & \\
\hline \multirow[t]{2}{*}{ Boxe } & Sim & $18(72,0 \%)$ & $7(28,0 \%)$ & 1,01 & $0,78-1,31$ & 0,946 \\
\hline & Não & $127(71,3 \%)$ & $51(28,7 \%)$ & & & \\
\hline \multirow[t]{2}{*}{ Futebol } & Sim & $14(60,9 \%)$ & $9(39,1 \%)$ & 0,84 & $0,60-1,17$ & 0,234 \\
\hline & Não & $131(72,8 \%)$ & $49(27,2 \%)$ & & & \\
\hline \multirow[t]{2}{*}{ Futsal } & Sim & $19(79,2 \%)$ & $5(20,8 \%)$ & 1,12 & $0,90-1,41$ & 0,372 \\
\hline & Não & $126(70,4 \%)$ & $53(29,6 \%)$ & & & \\
\hline \multirow[t]{2}{*}{ Jiu-Jitsu } & Sim & $22(71,0 \%)$ & $9(29,0 \%)$ & 0,99 & $0,78-1,27$ & 0,951 \\
\hline & Não & $123(71,5 \%)$ & $49(28,5 \%)$ & & & \\
\hline \multirow[t]{2}{*}{ Karatê } & Sim & $18(72,0 \%)$ & $7(28,0 \%)$ & 1,01 & $0,78-1,31$ & 0,946 \\
\hline & Não & $127(71,3 \%)$ & $51(28,7 \%)$ & & & \\
\hline \multirow[t]{2}{*}{ MMA } & Sim & $30(83,3 \%)$ & $6(16,7 \%)$ & 1,21 & $1,01-1,45$ & $0,081^{* *}$ \\
\hline & Não & $115(68,9 \%)$ & $52(31,1 \%)$ & & & \\
\hline \multirow[t]{2}{*}{ Muay-Thay } & Sim & $15(62,5 \%)$ & $9(37,5 \%)$ & 0,86 & $0,62-1,19$ & 0,302 \\
\hline & Não & $130(72,6 \%)$ & $49(27,4 \%)$ & & & \\
\hline
\end{tabular}

*: Teste exato de Fisher; RP: razão de prevalência; IC: Intervalo de confiança; ** Estatística significante. 
TABELA 3 - Variáveis envolvendo os protetores bucais

\begin{tabular}{llcc}
\hline Variáves & \multicolumn{1}{c}{ Categorias } & n & \% \\
\hline Conhecimento sobre Protetores & Náo & 18 & 7,3 \\
& Sim & 230 & 92,7 \\
Uso do Protetor & Não & 25 & 10,1 \\
& Sim & 223 & 89,9 \\
Uso Rotineiro & Não & 124 & 50 \\
Tipo de Protetor & Sim & 124 & 50 \\
& Pré-Fabicado & 36 & 14,5 \\
Grau de Importância & Termoplástico & 177 & 71,4 \\
& Individualizado & 10 & 4 \\
Uso de protetor no momento da lesão & Não & 158 & 63,7 \\
& Muito Importante & 87 & 35,1 \\
\hline
\end{tabular}

Sobre o tipo de lesão orofacial sofrida, as lesões de tecido mole (cortes nos lábios, gengiva, bochecha e língua) e as fraturas dentais foram as mais citadas pelos sujeitos, com respectivamente $24,6 \%(n=61)$ e $20,2 \%(n=50)$. Ademais, há de se destacar a presença de complicaçóes mais severas, a exemplo das fraturas e afundamentos de face e de crânio. A TABELA 4, versa sobre os tipos de lesóes sofridas pelos participantes da pesquisa.
Finalmente, de acordo com a TABELA 5, que analisa as variáveis sociais e contextuais da pesquisa com o uso do protetor, encontrase significância estatística quando os atletas conhecem os protetores $(\mathrm{p}=0,011)$ e quando consideram muito importante o uso durante a prática esportiva $(\mathrm{p}=0,065)$. O que gera uma enorme contradição entre teoria e prática. Os valores citados estáo em destaque.

TABELA 4 - Relação do tipo de lesão sofrida pelo esportista

\begin{tabular}{llcc}
\hline Variáves & Categorias & $\mathbf{n}$ & $\mathbf{\%}$ \\
\hline Tipo De Lesáo & Sangramento gengival & 10 & 4 \\
& Laceraçáo de tecido mole & 61 & 24,6 \\
& Fratura dental & 50 & 20,2 \\
& Deslocamento dental & 31 & 12,5 \\
& Perda dental & 20 & 8,1 \\
& Fratura facial & 12 & 4,8 \\
& Fratura craniana & 2 & 0,8 \\
& Afundamento ósseo & 8 & 3,2 \\
& Outros & 9 & 3,6 \\
\hline
\end{tabular}

TABELA 5 - Associação das variáveis do estudo com o uso do protetor bucal

\begin{tabular}{|c|c|c|c|c|c|c|}
\hline & & Náo & Sim & & & \\
\hline Variáves & Categorias & n (\%) & n (\%) & $\mathbf{R P}$ & IC 95\% & Valor de $\mathbf{P}$ \\
\hline \multirow[t]{2}{*}{ Sexo } & Masculino & $99(70,7 \%)$ & $41(29,3 \%)$ & 0,97 & $0,81-1,16$ & 0,737 \\
\hline & Feminino & $46(73,0 \%)$ & $17(27,0 \%)$ & & & \\
\hline
\end{tabular}


TABELA 5 - Associação das variáveis do estudo com o uso do protetor bucal

\begin{tabular}{|c|c|c|c|c|c|c|}
\hline & & Náo & Sim & & & \\
\hline Variáves & Categorias & n (\%) & n (\%) & $\mathbf{R P}$ & IC 95\% & Valor de P \\
\hline \multirow[t]{3}{*}{ Idade/Cat/Tercil } & Até 24 anos & $62(73,8 \%)$ & $22(26,2 \%)$ & 1 & - & 0,689 \\
\hline & 25 a 27 anos & $44(72,1 \%)$ & $17(27,9 \%)$ & 1,02 & $0,84-1,52$ & \\
\hline & $>27$ anos & $39(67,2 \%)$ & $19(32,8 \%)$ & 1,1 & $0,88-1,36$ & \\
\hline \multirow{2}{*}{$\begin{array}{l}\text { Grau de } \\
\text { Profissionalismo }\end{array}$} & Amador & $117(69,2 \%)$ & $52(30,8 \%)$ & 0,84 & $0,70-1,01$ & 0,122 \\
\hline & Profissional & $28(82,4 \%)$ & $6(17,6 \%)$ & & & \\
\hline \multirow{2}{*}{$\begin{array}{l}\text { Conhecimento } \\
\text { sobre Protetores }\end{array}$} & Sim & $138(73,8 \%)$ & $49(26,2 \%)$ & 1,69 & $0,96-2,96$ & $0,011^{* *}$ \\
\hline & Não & $7(43,8 \%)$ & $9(56,3 \%)$ & & & \\
\hline \multirow{2}{*}{$\begin{array}{l}\text { Uso do protetor em } \\
\text { algum momento }\end{array}$} & Não & $14(77,8 \%)$ & $4(22,2 \%)$ & 1,1 & $0,84-1,43$ & 0,532 \\
\hline & Sim & $131(70,8 \%)$ & $54(29,2 \%)$ & & & \\
\hline \multirow[t]{2}{*}{ Uso rotineiro } & Não & $74(76,3 \%)$ & $23(23,7 \%)$ & 1,14 & $0,96-1,36$ & 0,143 \\
\hline & Sim & $71(67,0 \%)$ & $35(33,0 \%)$ & & & \\
\hline \multirow[t]{3}{*}{ Tipo de protetor } & Pré-fabricado & $17(60,7 \%)$ & $11(39,3 \%)$ & 1 & - & 0,385 \\
\hline & Termoplástico & $106(72,1 \%)$ & $41(27,9 \%)$ & 0,84 & $0,61-1,15$ & \\
\hline & Fabricado pelo CD & $8(80,0 \%)$ & $2(20,0 \%)$ & 0,76 & $0,49-1,16$ & \\
\hline \multirow[t]{3}{*}{ Grau de importância } & Muito importante & $95(73,6 \%)$ & $34(26,4 \%)$ & 1 & - & $0,065^{* *}$ \\
\hline & Importante & $50(69,4 \%)$ & $22(30,6 \%)$ & 1,06 & $0,88-1,27$ & \\
\hline & Pouco importante & $0(0,0 \%)$ & $2(100,0 \%)$ & 0,26 & $0,20-0,35$ & \\
\hline \multirow[t]{3}{*}{ Tempo de prática esportiva } & Até 3 anos & $72(75,8 \%)$ & $23(24,2 \%)$ & 1 & - & 0,29 \\
\hline & 4 a 5 anos & $38(71,7 \%)$ & $15(28,3 \%)$ & 1,06 & $0,86-1,29$ & \\
\hline & $>5$ anos & $35(63,6 \%)$ & $20(36,4 \%)$ & 1,19 & $0,95-1,50$ & \\
\hline
\end{tabular}

*: Teste exato de Fisher; ${ }^{* *}$ : Estatística significante; RP: razão de prevalência; IC: intervalo de confiança.

\section{Discussão}

Mesmo que o avanço do discurso e das açóes que visam o equilíbrio entre os gêneros estejam bem consolidados, a prática esportiva continua sendo um território masculino. Dois fatores históricos parecem explicar esse fenômeno: a imposição física e a tradição cultural $^{12}$. Muitos estudos corroboram esse fato e os dados encontrados na pesquisa ${ }^{13,14}$. O contraponto fica por conta do trabalho de Almeida et al. ${ }^{15}$, que defenderam uma participação quase igualitária das mulheres em treinos e competiçóes esportivas, principalmente nas artes marciais.

Os adultos jovens representaram a principal faixa etária desse estudo, porém é válido ressaltar que o trabalho não levou em consideração os praticantes de esportes com menos de 18 anos, do contrário, de acordo com Tiwari et al. ${ }^{16}$, faria com que adolescentes e crianças representassem a maior porcentagem entre os sujeitos da pesquisa. Mesmo assim, apesar da iniciação cada vez mais precoce das crianças nos esportes coletivos e nas artes marciais, os adultos jovens representam a principal faixa etária da maioria dos trabalhos consultados, com uma média de idade de 27,4 anos no estudo de Cavalcanti et al. ${ }^{17}$, e de 24,1 anos no artigo de Di LeOne et al. ${ }^{18}$.

Pouco menos de $85 \%$ dos atletas entrevistados se declararam amadores e quase a metade deles relatou que praticam esportes a menos de três anos, apesar desse dado está bem de acordo com a literatura consultada $^{18,19}$, não foi possível identificar algum dado significativo que opusesse as atletas profissionais aos amadores.

A quase totalidade dos indivíduos $(92,7 \%)$ afirmou conhecer os protetores bucais e apenas 
$1,2 \%$ dos sujeitos $(n=3)$ os consideraram pouco importantes na prática esportiva. 223 esportistas $(89,9 \%)$ já usaram o protetor bucal em algum momento de sua vida esportiva, porém apenas $50 \%$ relataram o uso rotineiro. Apesar de o protetor bucal ser reconhecido como um dos mais eficientes equipamentos de segurança com utilização em diversas modalidades de esportes, seu conhecimento não é bem difundido ${ }^{20}$. O que é reforçado por um estudo israelense ${ }^{21}$. Contudo, alguns pesquisadores verificaram que os esportistas conhecem a importância do uso dos protetores bucais, em uma frequência que varia de $52,4 \%{ }^{22}$ a $83,2 \%{ }^{23}$, corroborando o resultado encontrado neste estudo, no qual $63,7 \%$ dos entrevistados escolheram a opçáa muito importante para classificar o uso de protetores bucais quando da prática de atividade esportiva.

Embora, apenas metade dos indivíduos ( $\mathrm{n}=124$ ) da presente amostra relatarem o uso rotineiro dos protetores bucais, esse resultado é bastante superior ao encontrado previamente ${ }^{24}$. Tal resultado, apesar de ainda superior, encontra similaridade nos estudos de BARBERINI et al. ${ }^{25}$, (2002) com $40 \%$ de uso rotineiro do protetor bucal por parte dos atletas.

Quase três quartos da amostra relatou a preferência pelo protetor termoplástico. Esses resultados conferem com os dados apresentados em outros estudos disponíveis na literatura consultada ${ }^{25}$. Já Di LEONE et al. ${ }^{18}$ atribuíram uma grande porcentagem de atletas que optam pelo protetor bucal tipo III, personalizado, destoando um pouco da maioria dos trabalhos.

Somente através da educação e consciência da eficácia dos protetores bucais, os atletas podem fazer uma escolha informada e optar pelo melhor protetor disponível. Os protetores bucais individualizados produzidos pelos cirurgiōes-dentistas garantem uma boa adaptação de mordida e uma boa estabilidade da ATM para prevenir injúrias orofaciais e concussōes ${ }^{8}$.

De todos os esportistas que responderam o questionário, um total de $203(81,9 \%)$ afirmou que sofreram alguma lesão orofacial quando praticava esportes. Mesmo que esse seja um dado bem significativo, é possível encontrar outros estudos com resultados bem equivalentes, a exemplo de um estudo brasileiro também com variedade de esportes que apresentou $73 \%$ dos entrevistados com algum trauma facial durante a carreira ${ }^{25}$ e de um estudo iraniano $^{13}$ com 79,2\%. Cavalcanti et al. ${ }^{17}$, em pesquisa realizada nas proximidades do presente levantamento, afirmam que quase dois terços da amostra de praticantes de artes marciais sofreram lesão facial. Levando em consideração apenas as artes marciais também, Di LEONE et al. ${ }^{18}$, concluíram que $46,3 \%$ dos lutadores tinham sofrido lesão orofacial. Além disso, 23,4\% das pessoas pesquisadas $(n=58)$ disseram que estavam usando protetor bucal no momento que sofreram a lesão. Dado $(28,5 \%)$ encontrado também em pesquisa recentemente publicada ${ }^{18}$.

Os traumas faciais mais sérios como o afundamento e a fratura de face e crânio, são os mais propensos a acontecer mesmo com o uso do protetor bucal, sendo assim, quando NAVARRO ${ }^{26}$ afirma que os protetores bucais aumentam a proteção contra concussóes cerebrais e lesóes mais severas, essa informação deve ser tratada com cautela. Todas as outras lesōes faciais e cranianas possuem chances equivalentes de machucarem os esportistas, girando em torno da casa de $75 \%$ quando do não uso do protetor bucal, o que mais uma vez justifica os esforços em fazer valer a obrigatoriedade dos protetores bucais em variados esportes.

LAGES et al. ${ }^{8}$ defendem de forma voraz que o aumento dos índices da utilização dos equipamentos de proteção só seria alcançado com a regulamentação do uso, tornando-o obrigatório nos esportes de contato. Defendem, também, que após a regularização, um movimento organizado de publicidade e informação seria capaz de mudar a realidade atual.

Devido ao seu espírito competitivo, a disciplina necessária e os benéficos efeitos fisiológicos dos esportes, estes são particularmente populares entre os jovens. No entanto, as preocupaçóes com alta incidência de lesôes são comuns entre pais e profissionais de saúde. Portanto, programas educacionais organizados pela classe odontológica se fazem necessários a fim de informar aos treinadores, atletas e familiares sobre as injúrias dentais e faciais advindas da prática esportiva e orientá-los quanto à importância do uso do protetor bucal durante a realização da atividade desportiva, principalmente as quem envolvem os esportes de contato ${ }^{17,18}$.

Baseando-se nos resultados apresentados, é possível afirmar que as lesôes orofaciais fazem parte da rotina dos atletas. No entanto, as pessoas envolvidas no meio esportivo como um todo ainda náo prestam a devida importância ao tema. Sendo assim, recomenda-se o surgimento de políticas de regularização do uso do protetor bucal nos esportes e também a divulgação dos benefícios que a proteção e a prevenção trazem aos atletas. 


\section{Abstract}

\section{Facial injuries and mouth guards}

The number of accidents that result in facial trauma is plentiful. The use of mouthguard is essential for the protection of the athletes. To conduct a survey with the intent of quantifying and qualifying the oral-facial injuries that result from the sports practice, as well as to draw a parallel with the use of mouthguard. A cross-sectional and descriptive study performed with 248 practitioners from 8 distinct sport disciplines from Paraiba and Rio Grande do Norte. The research involved the application of a questionnaire previously validated in the literature. The received data went through an statistical treatment using Fisher's Exact Test $(p<0.05)$ as well as a descriptive statistical analysis, utilizing the SPSS 20.0 software. Around $80 \%$ of the individuals have suffered a facial trauma during their sporting life, with the most common traumas being soft tissue injury and dental fracture. Almost all of the subjects $(92.7 \%)$ claimed to know mouthguard. 223 athletes (89.9\%) have used a mouthguard at some point in their sporting life, but only 50\% reported a routine use. Regarding the type of used mouthguards, the research shows the thermoplastic with $71.4 \%$ from the total $(n=177)$. Oral-facial injuries are part of the athletes routine. Nevertheless, people involved in sports as a whole don't pay the due attention to the subject. Therefore it is recommended the creation of policies for the regularization of the use of mouthguard in sports as well as the dissemination of the benefits that protection and prevention bring to the athletes.

KEYWORDS: Sports; Wounds and injuries; Dentistry; Oral health; Physical Education and training.

\section{Referências}

1. Sunar N, Fausto MCR. Atenção primária à saúde: a construção de um conceito ampliado. JMPHC. 2014;5(2):202-12.

2. Costa JM, Nogueira LT. Fatores associados à qualidade de vida relacionada à saúde de receptores de transplantes renais em Teresina, Piauí, 2010. Epidemiol Serv Saúde. 2014;23(1):121-9.

3. Fernandes ALO, Maia UMC, Knackfuss MI. Políticas públicas de promoção à saúde: uma análise da qualidade de vida e saúde de pessoas envolvidas em práticas corporais. Redfoco. 2014;1(1):11-21.

4. Santos P, Santos JC, Pereira CP. Assement of postraumatic orofacial damage based on portuguese civil, criminal and labor laws. Procrim. 2014;4:2-41.

5. Jacomin LS, Ito IH, Fernandes RA, Christofaro D. Estudos sobre arte marcial e lutas na literatura brasileira: revisão sistemática. Colloquium Vitae. 2013;5(2):149-57.

6. Ivkovic D. How to start the game. FIBA Assist Magazine [Internet]. 2006 [acesso 8 jul 2015];18:19-23. Disponível em: http:// www.kosarkarski-trenerji.com/ftp/fiba/a18.pdf

7. Gay-Escoda C, Vieira-Duarte-Pereira DM, Ardèvol J, Pruna R, Fernandez J, Valmaseda-Castellón EV. Study of the effect of oral health on physical condition of professional soccer players of the Football Club Barcelona. Med Oral Patol Oral Cir Bucal. 2011;16(3):436-9.

8. Lages FS, Rivera CP, Araújo DCE, Oliveira DWD. Protetor bucal para esportistas: relato de caso clínico. Rev Fac Odontol Lins Unimep. 2014;24(2):32-6.

9. Silveira JCS, Freitas DA, Oliveira SKM, Pereira MM. Relación del uso del protector bucal y traumatismo dental durante la práctica desportiva: revisión de la literatura. EFDeportes. 2012;16(164):1-9.

10. Souza JGS, Soares LA, Souza TCS, Pereira AR, Souza AGS. Traumatismos faciais decorrentes da prática esportiva. Rev Bras Cir Cabeça Pescoço. 2013;42(1):53-7.

11. Perunski S, Lang B, Pohl Y, Filippi A. Level of information concerning dental injuries and their prevention in Swiss basketball-a survey among players and coaches. Dent Traumatol. 2005;21(4):195-200.

12. Goelnner SV. Gênero e esporte na historiografia brasileira: balanços e potencialidades. Rev Tempo. 2013;19(34):45-52.

13. Shirani G, Motamedi MHK, Ashuri A, Eshkevari PS. Prevalence and patterns of combat sport related maxillofacial injuries. J Emerg Trauma Shock. 2010;3(4):314-7. 
14. McPherson M, Pickett W. Characteristics of martial art injuries in a defined Canadian population: a descriptive epidemiological study. BMC Public Health. 2010;10:795.

15. Almeida MAB, Corbett CA, Gutierrez, GL. O processo civilizatório da marcialidade e a figura feminina. Mov Percep. 2009;10(14):164-179.

16. Tiwari V, Saxena V, Tiwari U, Singh A, Jain A, Goud S. Dental trauma and mouthguard awareness and use among contact and noncontact athletes in central India. J Oral Sci. 2014;56(4):239-43.

17. Cavalcanti AL, Santos FG, Peixoto LR, Gonzaga AKG, Dias CHS, Xavier AFC. Ocorrência de injúrias orofaciais em praticantes de esportes de luta. Pesq Bras Odontoped Clin Integr. 2012;12(2):223-8.

18. Di Leone CCL, Barros IRCN, Salles AG, Antunes LAA, Antunes LS. O uso do protetor bucal nas artes marciais: consciência e atitude. Rev Bras Med Esporte. 2014;20(6):451-5.

19. Guedes DP, Silvério Netto JE. Motivos para a prática de esportes em atletas jovens e fatores associados. Rev Educ Fis UEM. 2013;24(1):21-31.

20. Woodward TW. A review of the effects of martial arts practice on health. WMJ. 2009;108(1):40-3.

21. Levin L, Zaik Y. Education on and prevention of dental trauma: it's time to act! Dent Traumatol. 2012;28(1):49-54.

22. Ferrari CH, Medeiros JMF. Dental trauma and level of information: mouthguard use in different contact sports. Dent Traumatol. 2002;18(3):144-7.

23. Tulunoglu I, Ozbek M. Oral trauma, mouthguard awareness, and use in two contact sports in Turkey. Dent Traumatol. 2006;22(5):242-6.

24. Biagi R, Cardarelli F, Butti AC, Salvato A. Sports-related dental injuries: knowledge of first aid and mouthguard use in a sample of Italian children and youngsters. Eur J Paediatr Dent. 2010;11(2):66-70.

25. Barberini AF, Aun CE, Caldeira CL. Incidência de injúrias orofaciais e utilização de protetores bucais em diversos esportes de contato. Rev Odontol Unicid. 2002;14(1):7-14.

26. Navarro RR. Protective equipment and the prevention of concussion - what is the evidence? Curr Sports Med Rep. 2011;10(1):27-31.

\begin{tabular}{|c|c|}
\hline $\begin{array}{r}\text { ENDEREÇO: } \\
\text { Yuri Victor de Medeiros Martins } \\
\text { Rua XII Irmãos, } 77-58600-000 \\
\text { Santa Luzia - BRASIL } \\
\text { e-mail: yurivictormm@gmail.com }\end{array}$ & $\begin{array}{l}\text { Recebido para publicação: 08/07/2015 } \\
1^{\text {a }} \text { Revisão: 22/10/2015 } \\
2^{\text {a }} \text { Revisão: 05/02/2016 } \\
\text { Aceito: 20/09/2017 }\end{array}$ \\
\hline
\end{tabular}

